This is the peer reviewed version of the following article: Cairney, P. and Studlar, D. (2014), Public Health Policy in the United Kingdom: After the War on Tobacco, Is a War on Alcohol Brewing? World Medical \& Health Policy, 6: 308-323. doi: 10.1002/wmh3.106, which has been published in final form at http://onlinelibrary.wiley.com/doi/10.1002/wmh3.106/full.

Paul Cairney, Professor of Politics and Public Policy, University of Stirling p.a.cairney@stir.ac.uk

Donley T. Studlar, Professor of Government and Public Policy, University of Strathclyde donley.studlar@strath.ac.uk

\title{
Public Health Policy in the United Kingdom: After the War on Tobacco, Is a War on Alcohol Brewing?
}

\begin{abstract}
The United Kingdom now has one of the most comprehensive tobacco control policies in the world, a far cry from its status two decades ago. Some influential public health voices have called for a similar campaign against alcohol consumption. But is the comparison appropriate? We identify the factors which were important in the relatively successful campaign for tobacco control, then analyse the obstacles and opportunities facing the movement for more stringent alcohol control. Alcohol policy today often bears a striking resemblance to tobacco policy pre-1990s, when the UK started on its path to becoming a leading regulatory on this policy.
\end{abstract}

'Every cigarette is doing you damage'. Irish anti-smoking slogan, adapted from Australia.

'There is no safe dose of alcohol' Professor David Nutt (2011)

\section{Introduction: from tobacco to alcohol control?}

Tobacco and alcohol are both 'legal addictions' that have attracted more public policy attention in recent years. There is a long history of attention to the dangers of consumption of these products, even if it is largely a history, of frustrated reformers, especially for alcohol (Baggott, 2011). There is also a more specific common element to both issues in recent times: medical and public health groups gather scientific evidence and use it to advocate policies designed to reduce health hazards. In both fields, we can identify two elements of the 'evidence based policymaking' (Cairney, 2014) process: the evidence generated to define a policy problem (unhealthy behaviour and its individual and social effects) and the policy proposals, such as higher taxes and stricter regulations, generated to combat it by seeking to minimise unhealthy behaviour.

The main concern for public health groups is the extent to which policy solutions relate to the scientific evidence. They would like the policy response to correspond directly to the evidence on the adverse effects of tobacco and alcohol use. Yet, the evidence-policy link often appears to be weak (the response is not proportionate to the problem) and/or delayed (a proportionate response takes a long time). A policy response may take decades to develop 
after the evidence was produced and generally accepted within the public health field. In some cases, it may happen long after the evidence is first accepted in government.

Today, the size of this gap varies markedly in tobacco and alcohol; public health ideas have been accepted, and used to inform policy choices, in very different ways. In tobacco, Cairney et al (2012) suggest that the gap between the problem and a proportionate response has been 20-30 years. Yet, UK tobacco control policies are close to international 'best practice'. Tobacco control policy is 'comprehensive' in the UK; it tops a major European public health league table (the 'Tobacco Control Scale') and represents a model for the rest of Europe (Joossens and Raw 2011; Cairney et al, 2012: 99; Levy et al.2012).

In comparison, alcohol policies are more limited, even though alcohol has been on the government agenda for far longer (Greenaway, 2003). Serious debate about whether alcohol should be treated similarly to tobacco, through a neo-prohibitionist restrictive regime, is only now beginning. Comparable evidence, suggesting unequivocally that alcohol is harmful to health, has not been accepted within government, which has continued to pursue a 'harm reduction' regime for alcohol, as it did for tobacco until the 1990s (Berridge, 2004; Thom, 2005). The major corresponding policy solutions - including minimum pricing and a ban on advertising and promotion - have not been adopted. According to the last major review, UK alcohol policy had a relatively 'low policy score' in the EU (Anderson and Baumberg, 2006: 374). Even if the evidence to underpin a neo-prohibitionist alcohol regime became stronger, we might find a significant delay in the passage of policies.

One key aspect to this process is the role of medical and public health scholarship. Numerous public health accounts link evidence-policy gaps, between the scientifically-identified size of the problem and an appropriate government response, to: (a) an initial reluctance of researchers to recommend specific policy responses; (b) a lack of public and governmental knowledge of the problem; (c) the strategies of industries, to deny the seriousness of the problem and lobby government to introduce limited policy responses; and/ or (d) an unwillingness of government to address the problem proportionately, perhaps because it fears a popular backlash (Cairney et al, 2012: 10-12; Oreskes and Conway, 2010). Further, public health scholarship is now closely linked to advocacy, that is, efforts to turn the evidence on harm into strong public health policy instruments.

The most recent major alcohol-control manifesto is Health First (Bauld et al, 2013). It was produced under the auspices of the Alcohol Health Alliance UK which is supported by 70 organisations, including groups focused solely on alcohol (e.g. Alcohol Concern), professional health groups (e.g. the British Medical Association and ten Royal Colleges of health professions), groups focused on cancer, heart disease, depression, liver disease, environmental health, men's health, policing, and addiction, and research institutes (including the UK Centre for Tobacco Control Studies) and universities (2013: 4). These groups are seeking ways to minimise the size of the evidence-policy gap, largely by learning from the tobacco policy experience, the strategies used by public health (and industry) groups in the past, and the scientific evidence on the policies introduced to reduce tobacco use (see Bauld et al. 2013: 10; 23-6; 38; British Medical Association, 2008). 
In this article, we provide important context to this campaign-focused comparison by providing a framework in which to compare tobacco and alcohol control policy. We do not analyse the relative merits or impacts of tobacco and alcohol control instruments. Rather, we explain, with reference to the political science literature on policymaking, why some instruments are selected (Cairney, 2012; Cairney et al, 2012; Greenaway, 2008a). We compare the modern history of UK tobacco and alcohol control policy to explain the adoption of relatively strong instruments in tobacco. Further, to go beyond a simple comparison of the properties of tobacco control ideas and their supporting evidence (is the evidence simply more persuasive in tobacco?) we identify the links between the exercise of power and the adoption of policies. We identify two main issues.

First, to understand how scientific evidence and policy solutions fare within political systems, we must examine the wider political contexts in which they are promoted, accepted and acted upon. Leading countries have moved from minimal to fully comprehensive tobacco control regimes in the post-World War II period (Studlar et al. 2011). In those countries, government choices have changed profoundly following changes in five key policy processes:

- institutional - departments of health took the major responsibility for tobacco policy

- agendas - tobacco was understood and addressed as a public health problem

- networks - public health groups became dominant over producers

- socioeconomic - taxation revenue, smoking and opposition to tobacco control fell

- ideas - the evidence on smoking related harm was 'set in stone' and governments learned from each other about how to address the problem (Cairney et al. 2012).

Change in these factors has been mutually reinforcing. For example, increased acceptance of the scientific evidence has helped shift the way that governments understand the tobacco problem. The framing of tobacco as a health problem allows health departments to take the policy lead. A decrease in smoking rates reduces the barriers to tobacco control; more tobacco control means fewer smokers.

Second, the evidence-policy gap might be reduced if alcohol control advocates learn from that experience. However, politics and policymaking varies markedly by policy issue (Lowi 1964; Freeman 1986). Consequently, we need to examine in-depth the differences between the alcohol and tobacco policy contexts, and the comparability of policy instruments designed to control or influence healthy behaviour.

To this end, we examine five key public policy processes to gauge the extent to which alcohol policy might emulate tobacco policy: the responsibility for policy decisions (which government department is primarily responsible for alcohol policy?); the ways in which the problem can be defined (is there a clear public health frame and a sense of urgency to solve the problem?); the status of pressure participants (what is the balance of power between public health groups and the alcohol industry?); the socioeconomic context (how important is alcohol tax revenue to government? Does the public support further alcohol control?); and the ways in which the scientific evidence is interpreted (does the government accept that there is no safe level of consumption?) and addressed (do governments draw on international action or policy lessons from other countries?). 


\section{Tobacco and Alcohol Policy: Five Key Factors}

\section{Has there been Institutional Change? UK Government Departments}

Health departments and organisations in the UK have taken the main responsibility for tobacco control, largely replacing departments focused on finance, agriculture, trade, industry and employment. The Treasury now supports a taxation regime designed to reduce tobacco demand (Cairney et al, 2012: 114) and, in 2002, it identified smoking as the biggest cause of health inequalities (Cairney, 2007: 62). This shift changes some important rules of tobacco policymaking: health departments are the most likely to frame tobacco as a health problem and consult with health groups.

Greenaway (2011: 411) describes alcohol as subject to greater fluctuations in responsibility according to how the issue was 'framed'. There is the same historical sense of crossdepartmentalism in both areas but, in alcohol, non-health departments still sometimes take the policy lead. Before the 1950s, alcohol policy was rarely seen as a responsibility of the health department. A key focus was licensing law on the sale of alcohol. Further, the main pressure on government to act came from the 'temperance' movement which focused on moral and social obligations rather than health (Greenaway, 1998; Berridge, 2013).

Even in the 1950s, the Ministry of Health treated alcohol consumption as a social, not a health problem (people were free to drink unless they engaged in anti-social behaviour), and even then it was reluctant to take responsibility (Greenaway, 2003: 158). It resisted, for some time, the argument put forward by psychiatrists (backed by work in the US and by the WHO) that alcoholism was a treatable 'medical disease' (2003: 159). Then, the disease frame took hold, but with the effect of limiting the target of alcohol policy to a small section of the population. Government concern with the 'drinking habits of the nation' was largely a 'post1970 focus' (2003: 165), made more complicated by the context of a growing liberal attitude to social behaviour. 'By contrast, attitudes towards tobacco consumption became markedly more censorious' (Greenaway 2003: 175).

During this time, other departments took the lead (Thom, 1999: 5). For example, the Ministry of Transport gradually oversaw efforts to reduce 'drunk-driving' from the 1950s, as the evidence on the effect of alcohol on driver responses became increasingly accepted in government, the technology developed to test blood alcohol levels, and public attention rose (Greenaway, 2003: 167). Spending on drunk-driving campaigns was much higher than for health education on drinking at least until the 1980s. This imbalance in response was partly because of the availability of, and government receptivity to, the evidence: the medical interpretation of alcoholism as a disease was 'unclear and always shifting'; the drunk-driving issue had largely been addressed after a surge of public concern, producing a technical debate about the effectiveness of policy (Greenaway 2003: 173-4; note the nomenclature shift to describe 'drink-driving' in the UK). Notably, the health department is mentioned rarely in Greenaway's (2003) analysis, partly because the issues were naturally addressed by transport and policing departments, and partly because alcohol industry groups managed to contain the 
issue to transport safety. This furthered a historical tendency either to minimise the role of the state in alcohol control, or restrict its involvement to discrete issues (Nicholls, 2009: 199).

Thus, even by the 1970s, the UK's health department was relatively new to alcohol, whereas it had been an active participant in tobacco control for some time. Its role became clearer from the 1970s when it accepted a 'problem drinking' (rather than 'alcoholism') frame, which widened its target population, and the Home Office transferred more responsibility for 'habitual drunken offenders'. In the late 1970s it was influenced by the 'consumption model', which linked alcohol abuse to overall levels of drinking in society, coupled with evidence of rising consumption in the UK from the 1950s. Policy became overseen by health ministers sympathetic to alcohol control, and the health department became a focal point for increasingly well-funded and organised (albeit from a low base) public health groups. It was also able to draw on its experience on tobacco control, especially in health education, taxation and advertising (Greenaway 2003: 177).

Even as the health department role grew, it shared responsibility on measures such as taxation (Customs and Excise) and advertising (the Advertising Standards Authority) (Greenaway 2003: 177; Baggott, 2011: 350; Baggott, 2010: 136). It does not control alcohol licensing and, therefore, periodically arising issues such as binge drinking (in relation to opening hours) and football hooliganism (Greenaway, 2003: 181; Greenaway, 2011: 417). For example, the 2003 Licensing Act for England and Wales was led by the Home Office (before being taken over by the Department for Culture, Media and Sport, DCMS). This came at a time (mid-2000s) when the Department of Health stalled on a wider Alcohol Harm Reduction Strategy for England (AHRSE) and measures such as increasing tax to reduce demand were 'ruled out largely on grounds of political and bureaucratic expediency' (Greenaway 2011: 417; 425). Indeed, Greenaway (2011: 418) describes the health department's frequent reluctance to take the lead on alcohol, with its Health Secretary and ministerial team lukewarm to reform (and/ or focused on issues such as National Health Service reform or illicit drug use) and its drug professionals 'reluctant to consider alcohol abuse in the same category as drug abuse'. AHRSE was taken up by the Prime Minister's Strategy Unit, designed to tackle cross-cutting issues (Greenaway, 2011: 419).

\section{Has there been Institutional Change? The multi-level context}

In alcohol and tobacco, there has been a significant shift of policy responsibility to other levels and types of government: policies may be made at the devolved, UK and EU levels and there may be a role for the courts, as in minimum unit pricing in Scotland. However, they display markedly different histories: in tobacco, international action has often provided further impetus for control; international action on alcohol is relatively new, with the exception of the WHO, and there is a greater mix of actors for and against further control. This reflects a traditionally wide range of country level views, from Nordic patterns of restriction to Southern European patterns of alcohol normalisation (based partly on 'drinking cultures' and the influence of wine producers in the South) and mixed views within alcohol control groups, seeking either controls on alcohol use in general or alcohol abuse in particular (Princen, 2007: 25; 27). 
Significant health and social policy on alcohol only arose in the EU in the mid-1990s, following Swedish concerns over the effect of EU membership on its alcohol controls. It focused on areas such as alcohol consumption and drink-driving by young people (Princen 2007: 26). The European Commission only took steps towards an anti-alcoholism strategy in 2005, focusing on 'soft instruments', including education, 'self-regulation' and funding alcohol control groups, on youth, driving and advertising. Further, there is a much longer history of economic-related alcohol policy in the EU, with a strong orientation towards trade liberalisation (Princen 2007: 25). This contrasts with tobacco policy, subject to a public health perspective in the EU since the mid-1980s.

As in tobacco, there is a clearer alcohol control agenda in Scotland (Hawkins and Holden, 2013: 58; Cairney, 2007). The Scottish Government has responsibility for health and criminal justice, but not economic or trade, policy. It has used these powers recently to foster a pricebased approach to reducing alcohol consumption - including a ban on sales promotions and the introduction of a minimum unit price for alcohol (subject to comment by the European Commission after consultation with member states). A similar policy has stalled at the UK Government level which, instead, promised to ban the sale of alcohol below the cost of its sales taxes (Hawkins et al, 2012: 299).

\section{Is the Problem Framed Differently and High on the Government Agenda?}

Smoking was once seen as normal and tobacco was once viewed primarily as a product with economic value; tobacco growing and manufacturing were often subsidised or encouraged. Now, smoking is being increasingly 'denormalized' and is largely viewed as a public health epidemic or even a moral problem (Cairney et al. 2012: 213-4). This is the frame that many alcohol control groups would like to adopt. For example, Bauld et al (2013: 10) argue that: 'Every year in the UK, there are thousands of deaths, hundreds of thousands of hospital admissions and over a million violent crimes linked to drinking alcohol'. They estimate the 'personal, social and economic cost of alcohol' at over £60bn in the UK (2013: 6).

Yet, for long periods of history, drunkenness has been 'culturally acceptable' behaviour, only challenged recently (Berridge, 2013: 31; 233; Nicholls, 2009: 233). The risk of 'moderate' or 'heavy' alcohol consumption is less clear, and it still has a reputation for providing some health benefits if taken in small quantities (Yeomans, 2013; Greenaway, 2008a: 491). Further, alcohol sales are still linked strongly to the importance of tax revenue, jobs (often in rural areas with limited alternatives), tourism, exports and a 'night time economy'. The industry blames sensational media for exaggerating its ill effects (Hawkins and Holden 2013: 60). ${ }^{i}$ Further, the problematic use of alcohol is more likely to be linked to crime or anti-social behaviour than health; there is a different sense of public harm. Therefore, tobacco control, as a public health policy, appears to be more straightforward and conducive to a coherent abstinence-based control strategy. While the idea of 'harm reduction' has not disappeared (in fact, the invention of e-cigarettes has reignited the debate), it is less apparent than in fields such as illicit drugs and alcohol use. 
In alcohol, it is more difficult to shake off the idea that public health controls would hurt the economy and punish people for engaging in legal behaviour - a 'nanny state' argument heeded by Conservative governments (Baggott, 2011: 351). The alcohol industry also promotes, generally successfully, the idea that most people drink sensibly and that governments should focus on 'high risk' or 'problem' drinkers rather than demonise general consumption (Hawkins et al, 2012: 302; Hawkins and Holden, 2013: 59; Nicholls, 2009: 2167).

This understanding of the problem is crucial to the way in which it is 'solved' (note that, in political science, 'solved' or 'solution' refers to the way in which policymakers think about, and governments address, a problem - without implying that the choice is appropriate or the solution is effective). For example, a general social problem might be solved with uniform measures such as regulations/ bans on advertising and high prices, while a problem relating to individuals may be addressed with specific medical and police interventions, coupled with a general commitment, through education and information, to tackle a binge drinking culture in some social groups (although note that the Scottish Government justified its minimum unit price legislation as a way to deal with 'harmful and hazardous' drinkers - McCulloch, 2014). The choice of solutions also takes place in the context of continued industry influence - and its general industry strategy is to describe uniform and strong control measures as 'blunt' and/ or 'unworkable' tools, made worse by poor consultation with the industry (Hawkins and Holden, 2013: 55).

The history of alcohol control is one of multiple and shifting frames used by different, influential actors within the policy process - including moral, 'disease', epidemiological, and criminal justice (Thom, 1999: 15-7; 96). A shift from moral/ temperance to psychiatric/ scientific influence began in the 1950s, when government (and much medical) attention to alcohol consumption as a problem was low (Thom, 1999: 49 describes one main effect: the development, over three decades, of 'alcoholism treatment units'). The advent of the 'new public health' in the 1970s focusing on noncontagious, behavioural health hazards, had some effect (Thom 2005) and 'preventive health', focusing on consumption in the whole population eventually became a more persuasive model in the health department (Greenaway, 2008a: 488). However, this ability to present multiple frames, and the legacy of limited historical control, is reflected in relatively slow change in alcohol policy.

Starting in the 1980s, there was a shift in UK policy in alcohol but from a much lower base and with a less clear direction than tobacco. Alcohol was included regularly in broad public health strategies designed to promote the reduction of unhealthy behaviour, but the government was not committed to a broad socio-economic approach to alcohol control. Instead, it often based solutions on a specific 'disease' model and/or a focus on youth or other sub-groups (Nicholls, 2009: 217). It tended to adopt education-based measures rather than direct regulation. In the Conservative Government era (1979-1997) there was: a focus on problem individuals or groups; a broad rejection of tax, price, or other measures to reduce demand or availability; an emphasis on health education on the risks of drinking; a 'relaxation of licensing'; and, a tendency to rely on voluntary 'industry self-regulation 
measures on advertising and under-age drinking' (Baggott, 2010: 137; 2005). These measures are similar to those in tobacco policy, 1960s-1990s.

Baggott (2005; 2010: 140; 143) identifies some change in UK government strategy from the election of Labour in 1997 - including more police powers to deal with premises associated with under-age drinking or anti-social behaviour - but several similarities: an unwillingness to 'regulate price and availability'; a focus on "'high risk' groups rather than on the wider population"; and, a continuation of voluntary agreements with industry on areas such as advertising and health education. During this time, the replacement of ineffective voluntary measures with legislation was a key turning point in tobacco control (Cairney, 2007).

The Labour government continued with the use of multiple 'frames' to justify alcohol control. According to Greenaway (2011: 413-6), the 2003 Licensing Act for England and Wales' 'muddled' rationale was simultaneously: economic, including a driver to enhance urban regeneration by reducing 'red tape' for business and allowing town centres to remain as hubs for drinking; 'progressive', by signalling a move from 'nanny state' regulation towards policies based on encouraging a 'continental-style' drinking culture (reflecting a longer term trend towards liberalisation of licensing laws); pro-local authority, by shifting many powers from magistrates; and aimed at reducing public disorder, by liberalising the law on opening hours to address late-night disorder. Its stated rationale was to: 'protect children from harm'; 'prevent public nuisance'; 'promote public safety'; and, 'prevent crime and disorder'. In either description, its public health rationale was limited - unlike in Scotland, this was not a stated objective (Baggott, 2010: 138-9).

A further strategy during Gordon Brown's tenure as Prime Minister (2007-10) was to introduce targets (cross-departmental, led by the Home Office) to reduce hospital admissions and 'public perceptions of drunk or rowdy behaviour' and make a broad commitment to study the links between 'alcohol pricing, promotion and harm', while the 2008 budget saw some commitment to raising the price of alcohol above inflation, while the government criticised supermarkets for artificially low prices (Baggott 2010: 144-5).

Overall, alcohol can still be framed as an issue of disorder (via Home Office) and/ or economic development and tourism (via the DCMS). The UK Government's most recent alcohol strategy ( $\mathrm{Cm} 8386,2012)$ also focuses on the anti-social consequences of 'binge' drinking. A comparison with tobacco control highlights the absence of two key policy measures - on advertising/ promotion and pricing - that would be associated with treating alcohol control as a pressing public health problem. The industry still has the ability to advertise alcohol - advertising expenditures vastly overshadow those spent on health education and, compared to tobacco, there is a relative lack of product warnings on the ill effects of alcohol consumption. The current UK Government has also delayed indefinitely the introduction of a minimum unit price on a unit of alcohol.

Has the Balance of Power Shifted Between Participants? 1. The industry.

The World Wars produced a very close and enduring relationship between the government and tobacco industry because the latter were seen as patriotic for providing a morale-boosting 
product to the troops (Cairney et al, 2012: 48). Policy was coordinated by finance-related departments, and tobacco companies were the most consulted. In contrast, the UK government saw its control of alcohol use as a key to the war efforts.

Yet, now, it seems easier to 'demonise' tobacco companies. In particular, there is muchreduced support for tobacco company denials of the health hazards of smoking, epitomized in the testimony of tobacco company executives before a US Congressional committee in 1994, and exposed by the widespread release of damaging internal tobacco company documents (Cairney et al, 2012: 132; Studlar, 2002).

There are some recent examples of similar criticisms of the alcohol industry (PLoS Medicine Editors, 2011; McCambridge et al, 2013). However, it has not lost its 'traditionally privileged and powerful position within the policy process' (Baggott, 2010: 137). ${ }^{\text {ii }}$ Alcohol selling companies are still well regarded and consulted regularly, even during the production of public health plans (Baggott, 2005: 234; Hawkins et al, 2013; Holden and Hawkins, 2012). Some companies are still respected for their positive contribution, particularly by departments focused on trade and economic growth.

From the mid to late 2000s, Baggott (2010: 147) detects a 'tougher stance' and willingness of the UK Government to replace voluntary with statutory codes of industry practice. There is also a greater government willingness to consult the public as well as the industry. However, the routine influence of the alcohol industry has not diminished in the same way as tobacco companies (Cairney, 2007: 47; Baggott, 2011: 412). Instead, it has maintained 'partnership' status to ensure regular consultation with government and the chance to influence policy further through implementation (Hawkins et al, 2012: 301; Berridge 2005a; Baggott 2005; 2006).

This relationship can be identified at several levels of government. In the UK, Baggott (2010: 136-7) describes the Labour Government's 'unashamedly pro-business' social policy strategy, arguing that legislation to reform licensing in 2003 was prompted by industry demands for longer hours in pubs and off-licenses, and identifying a significant commitment to joint-working with the industry on the AHRSE (2010: 139). In the EU, Princen (2007: 25) discusses a strong orientation towards trade liberalisation, an economic frame, and a focus on 'problem' drinking - allowing the industry to play a central role in consultation (Princen 2007: 25). Even in Scotland, manufacturers and sellers have a stronger role, not only in consultation, albeit sometimes when a decision already has been made, but also in their efforts to oppose restrictive policies through the courts (Holden and Hawkins, 2012; Cairney and McGarvey, 2013: 167; BBC News, 2013).

\section{Public health groups and the public health strategy.}

In tobacco, public health groups are now more likely to be consulted and tobacco companies are often deliberately excluded. Anti-smoking groups in the UK were relatively poorly funded (ASH) or disorganised (the BMA) until the mid-1980s, but they have now become key players within government. ASH was established by the Royal College of Physicians in 1971 and has been funded by the Department of Health (Berridge 2005a; Cairney et al, 2012: 
103). The 1970s/80s onwards saw a major shift in public health campaigns, from harm reduction to neoprohibitionism, and a rise in spending on such campaigns, made more significant when tobacco advertising was banned (Berridge, 2004; Berridge and Loughlin, 2005). In other words, the power of these groups has been reinforced by the growing trend towards absolutist tobacco control.

In contrast, the Alcohol Health Alliance was not established until 2007 and the shift towards a more absolutist approach to alcohol control is in its relative infancy. Voluntary groups grew from the 1950s, and alcohol control groups mobilised from the 1960s and 70s, but the mix of groups was wider than in tobacco, reflecting a greater likelihood that alcohol policy would cross departmental boundaries frequently (Thom, 1999: 13-4; 67). Broad alliances contain more social work, policing and voluntary groups, with different goals (Baggott, 2011: 350; Greenaway, 1998). Until very recently, key alcohol control groups, such as the Royal College of Physicians, have felt like 'new kids on the block' and unaware of the 'enormity' of the control agenda (Greenaway 2011: 418).

\section{Has the Socioeconomic Context Changed Markedly?}

The socioeconomic context can be broken down into economic factors and social attitudes and behaviour. The economic benefit of tobacco production and consumption has fallen dramatically in the post-war period, making it less significant to the Treasury. Tobacco taxation as a proportion of total taxation has fallen from 16\% in 1950 to below $4 \%$ (Cairney et al, 2012: 114). The number of smokers has declined markedly, from $82 \% / 41 \%$ in men and women in 1948, to $22 \% / 21 \%$ in 2008 (2012: 115). Opposition to tobacco control has declined, and, crucially, people have become more supportive after measures were introduced (2012: 115-7).

In comparison, the alcohol economy may now be more important and drinking is still a normal part of life, but there is not always a stronger level of opposition to further controls:

- Total alcohol duties are now approximately the same as those for tobacco - over $£ 10$ bn per year (Rogers, 2013) and the economic frame is geared towards the role of the 'night time economy' (Hawkins and Holden, 2012: 301).

- Drinking prevalence is more difficult to gauge, falling into several categories: 1) did you drink last week? 2) Did you drink on at least 5 days last week? 3) Did you binge drink? The meaning of the latter is difficult to pin down (Nicholls, 2009: 234), either referring to a specific level, double the recommended daily amount, or an attitude relating to setting out to get drunk ('moderation' is also difficult to define - Yeomans, 2013' Greenaway, 2008a: 495-6). The self-reported levels in 2010 were 67/17/19\% in men and 53/10/13\% in women (House of Commons Library, 2012: 6).

- Figures from public health groups identify a permissive consensus on further alcohol controls (Institute of Alcohol Studies, 2010; Bauld et al, 2013; compare with Greenaway, 2008a: 495 on 'the libertarian nature of public opinion'), but opinion is divided on specific measures such as a minimum unit price of alcohol (YouGov, 2012a; 2012b). 
The production and dissemination of the scientific evidence linking smoking to ill health has been accepted within government circles. For example, a report by SCOTH (Scientific Committee on Tobacco and Health) in 1998 marked governmental acceptance of the scientific evidence on passive smoking (Cairney, 2007; Aspect Consortium, 2004: 34).

The equivalent in alcohol policy is difficult to identify, and scientific evidence may play a longer term 'enlightenment' role than have a direct impact (Thom, 1999: 11-12). Further, the alcohol industry is still involved in the research process underpinning government policy through the 'Portman Group' and 'Social Aspects Organisations' (which exist partly to deliver voluntary measures) and by funding scientific research in a way no longer available to tobacco companies (Baggott, 2010: 140). Hawkins et al (2012: 301) find it 'remarkable' that 'current UK alcohol policies are far closer to policies advocated by the alcohol industry than those indicated by the prevailing evidence base'. The health debate continues with, for example, public health groups challenging the view that there is any beneficial level of alcohol consumption (Nutt, 2011; Møller, 2014) and seeking, in a field where it is relatively difficult to measure the risk and impact of consumption (Yeomans, 2013; Thom, 1999: 12930 ), to identify a mix of indicators of alcohol-related harm and convince policymakers of the need for further action (see for example, Bauld et al, 2013: 6-10; House of Commons Library, 2012; Baggott, 2010: 135; 2011: 348-9; Plant and Plant 2006).

The hope, within public health, of policy being driven primarily by the growing scientific evidence on alcohol-related harm has been frustrated. For example, the Home Office has been accused of 'cherry picking evidence' to generate support for the idea that late night sales licenses were beneficial to communities - by reducing anti-social behaviour at fixed times and reducing binge drinking associated with closing times at pubs (Baggott 2011: 424; Greenaway, 2008a: 491). Baggott (2010: 138) argues that the evidence suggested the opposite case, and that the policy came before the evidence. Further, while the policy was challenged significantly in media coverage and, to some extent, in Parliament, this related to 'moral panics' about the social, not long term health, effects of 'binge drinking' (Baggott 2011: 425; Greenaway 2008b: 9). Baggott (2010: 140) argues that this questionable link between public health group-led evidence and policy is still a general feature in alcohol.

As in tobacco, it may be that the acceptance of alcohol-related evidence in governments can be accelerated by international organisations. However, the balance between public health and economic frames in EU policy seem more oriented towards public health in tobacco, but political economy in alcohol (Princen 2009; Baggott 2011: 360). The WHO has played a strong postwar role and, by 2010, had developed a stronger global alcohol control strategy, informed by the 'no safe level' argument (Møller, 2014), but has not initiated an equivalent to the WHO Framework Convention on Tobacco Control (Thom, 1999: 28-31; Baggott, 2011: 359). The latter took approximately 25 years to develop after the WHO began to make pronouncements about tobacco (Cairney et al. 2012). The WHO has campaigned against alcohol hazards for an even longer time and, more recently, has recommended that the drinks industry be excluded from policymaking on this issue. However, it is more difficult to 
develop an international consensus, particularly in countries with long histories of failed prohibition (Schrad 2010; the UK was not affected by prohibition but has been influenced by US research and policy - Greenaway 2003; Thom 2005; Berridge 2005b).

\section{Conclusion: The Broader Context of Evidence Based Policy}

The article situates the role of scientific evidence within a broad account of the policy process. It suggests that policymakers make choices within a policy environment consisting of five interacting processes involving institutions, agendas, networks, socioeconomic factors, and ideas/ beliefs. The nature of this policymaking environment influences the extent to which scientific evidence, and the solutions it helps generate, is accepted in government and used to produce a policy response that is consistent with the evidence. This process may take a remarkably long period of time. For example, we argue that, in leading tobacco control countries, it took 20-30 years to close the 'evidence-policy gap'.

We draw on this experience of tobacco control to suggest that alcohol control may only become as 'comprehensive' if some broad conditions are met: the department of health takes the lead on policy, at each level of government; the issue is framed dominantly as a public health problem requiring urgent attention; public health/ medical groups are consulted in government at the expense of the industry; the government does not value sales income and economic benefits over the broader socio-economic costs of consumption; public opinion is not against control measures; the evidence is accepted across departments in government; and, governments learn from the experience of others when introducing control measures.

In other words, at least in politics, there is no such thing as self-evident truths that sweep old ideas aside. The process of turning evidence into policy is a battle like any other. In alcohol policy this is still to be waged in areas such as advertising and promotion, health warnings and education, and minimum unit pricing. Further, based on current evidence, and the experience of tobacco, it may take a long time, if ever, to be successful.

\section{References}

Advertising Standards Authority (2013) 'Our History' http://www.asa.org.uk/AboutASA/Our-history.aspx

AHRSE (Alcohol Harm Reduction Strategy for England) (2004) London: Cabinet Office, Prime Minister's Strategy Unit.

Alcohol Concern (2010) 'Review of Alcohol Taxation and Pricing' (Submission to Treasury) http://www.alcoholconcern.org.uk/assets/files/PolicyandCampaigns/HMT__alcohol_tax_and_price_review_August_2010.pdf

Anderson, P. and Baumberg, B. (2006) Alcohol in Europe: A Public Health Perspective (A Report for the European Commission) http://ec.europa.eu/healtheu/news_alcoholineurope_en.htm

Aspect Consortium (2004) Tobacco or Health in the European Union - Past, Present and Future (Luxembourg: Office for Official Publications of the European Communities) http://www.europeancancerleagues.org/DOSS/uploaded/182_tobacco_fr_en[1].pdf 
Baggott, R. (2005) 'From Sickness to Health? Public Health in England', Public Money \& Management, 25, 4, 229-236.

Baggott, R. (2006) Alcohol Strategy and the Drinks Industry: A Partnership for Prevention? York: Joseph Rowntree Foundation.

Baggott, R. (2010) 'A modern approach to an old problem? Alcohol policy and New Labour', Policy and Politics, 38, 1, 135-52.

Baggott, R. (2011) Public Health Policy and Politics $2^{\text {nd }}$ Edition (Basingstoke: Palgrave).

Bauld, L. et al (2013) Health First: An Evidence-based alcohol strategy for the UK (Stirling: University of Stirling) www.stir.ac.uk/management/about/social-marketing

BBC News (2013) 'Minimum pricing: Challenge to Scottish alcohol legislation fails' 3 May http://www.bbc.co.uk/news/uk-scotland-scotland-politics-22394438

Berridge, V. (2004) 'Militants, Manufacturers, and Governments: Postwar Smoking Policy in the United Kingdom', in E. A. Feldman and R. Bayer (eds) Unfiltered: Conflicts over Tobacco Policy and Public Health (Cambridge: Harvard University Press).

Berridge, V. (2005a) 'Issue Network versus Producer Network? ASH, the Tobacco Products Research Trust and UK Smoking Policy'. In V. Berridge (ed) Making Health Policy: Networks in Research and Policy after 1945. New York: Rodopi.

Berridge, V. (2005b) Temperance: Its History and Impact on Current and Future Alcohol Policy. York: Joseph Rowntree Foundation.

Berridge, V. (2013) Demons: our changing attitudes to alcohol, tobacco and drugs (Oxford: Oxford University Press)

Berridge, V. and K. Loughlin (2005) 'Smoking and the New Health Education in Britain 1950s-1970s', American Journal of Public Health, 95(6): 956-94

British Medical Journal (1967) 'Road Safety Act, 1967', 4, 39 http://dx.doi.org/10.1136/bmj.4.5570.39

British Medical Association (2008) Alcohol misuse: tackling the UK epidemic (London: BMA) http://www.dldocs.stir.ac.uk/documents/Alcoholmisuse.pdf

Cairney, P. (2007) 'A "Multiple Lenses" Approach to Policy Change: The Case of Tobacco Policy in the UK', British Politics, 2(1): 45-68

Cairney, P. (2012) Understanding Public Policy (Basingstoke: Palgrave)

Cairney, P. (2014) 'If You Want to Inject More Science into Policymaking You Need To Know the Science of Policymaking', paper to Political Studies Association Conference http://www.psa.ac.uk/sites/default/files/conference/papers/2014/Cairney\%20PSA\%202014\% 20EBPM\%2028.2.14_0.pdf

Cairney, P. and McGarvey, N. (2013) Scottish Politics $2^{\text {nd }}$ Ed. (Basingstoke: Palgrave)

Cairney, P., Studlar, D. and Mamudu, H. (2012) Global Tobacco Control: Power, Policy, Governance and Transfer (Basingstoke: Palgrave) 
Cm 8386 (2012) The Government's Alcohol Strategy (London: TSO) https://www.gov.uk/government/uploads/system/uploads/attachment_data/file/98121/alcoholstrategy.pdf

Freeman, G. (1986) "National Styles and Policy Sectors: Explaining Structural Variation," Journal of Public Policy 5 (1985): 467-95.

Greenaway, J. (1998) 'Policy Learning and the Drink Question in Britain 1850-1950', Political Studies, 46, 5, 903-18

Greenaway, J. (2003) Drink and British Politics since 1830: A Study in Policy Making (Basingstoke: Palgrave Macmillan)

Greenaway, J. (2008a) 'Agendas, venues and alliances: New opportunities for the alcohol control movement in England', Drugs: education, prevention and policy, 15, 5, 487-501

Greenaway, J. (2008b) 'The Politics of Drink: Research on New Labour and Alcohol 19972005', Paper for PAC Conference, York, September

Greenaway, J. (2011) 'How policy framing is as important as the policy content: The story of the English and Welsh Licensing Act 2003', British Politics, 6, 4, 408-29

Hastings, G et al (2010) 'Failure of self regulation of UK alcohol advertising', British Medical Journal, 340, 184-6 http://dx.doi.org/10.1136/bmj.b5650

Hawkins, B. and Holden, C. (2013) 'Framing the alcohol policy debate: industry actors and the regulation of the UK beverage alcohol market', Critical Policy Studies, 7:1, 53-71 http://dx.doi.org/10.1080/19460171.2013.766023

Hawkins, B., Holden, C. and McCambridge, J. (2012): Alcohol industry influence on UK alcohol policy: a new research agenda for public health', Critical Public Health, 22:3, 297305 http://dx.doi.org/10.1080/09581596.2012.658027

Holden, C. and Hawkins, B. (2012) "Whisky gloss": the alcohol industry, devolution and policy communities in Scotland', Public Policy and Administration, http://ppa.sagepub.com/content/early/2012/07/26/0952076712452290.abstract

House of Commons Library (2012) Statistics on Alcohol (SN/SG/3311) www.parliament.uk/briefing-papers/sn03311.pdf

Institute of Alcohol Studies (2010) Public Opinion on Alcohol and Alcohol Policy http://www.ias.org.uk/resources/factsheets/public_opinion.pdf

John, P. (2012) Analyzing Public Policy (London: Routledge)

Joossens, L. and M. Raw (2011) 'The Tobacco Control Scale 2010 in Europe'. Paper presented at European Conference on Tobacco or Health, Amsterdam.

Levy, D.T., L. Currie, and L. Clancy. 2012. 'Tobacco Control Policy in the UK: Blueprint for the Rest of Europe?’ European Journal of Public Health

Lowi, T. (1964) 'An American Business, Public Policy, Case-Studies, and Political Theory', World Politics, 16, 4: 677-715. 
McCambridge J, Hawkins B., Holden C. (2013) 'Industry Use of Evidence to Influence Alcohol Policy: A Case Study of Submissions to the 2008 Scottish Government Consultation', PLoS Med 10, 4, e1001431. doi:10.1371/journal.pmed.1001431

McCulloch, A. (2014) 'Scottish Minimum Alcohol Pricing and EU Law' http://papers.ssrn.com/sol3/papers.cfm?abstract_id=2394018

Møller, L. (2014) 'EU has 'highest' level of alcohol use and related harm', The Parliament http://www.theparliament.com/latest-news/article/newsarticle/eu-has-highest-level-ofalcohol-use-and-related-harm/\#.UxngLsZFCU1

Nicholls, J. (2009) The Politics of Alcohol (Manchester: Manchester University Press)

Nutt, D. (2011) 'There is no such thing as a safe level of alcohol consumption', The Guardian, $7^{\text {th }}$ March http://www.guardian.co.uk/science/2011/mar/07/safe-level-alcoholconsumption

Oreskes, N. and Conway, E.M. (2010) Merchants of Doubt: How a Handful of Scientists Obscured the Truth on Issues from Tobacco Smoke to Global Warming (New York: Bloomsbury Press).

Plant, M. and Plant, M. (2006) Binge Britain: Alcohol and the National Response. Oxford: Oxford University Press.

PLoS Medicine Editors (2011) 'Let's Be Straight Up about the Alcohol Industry', PLoS Med 8, 5, e1001041. doi:10.1371/journal.pmed.1001041

Princen, S. (2007) 'Advocacy Coalitions and the Internationalization of Public Health Policies', Journal of Public Policy, 27, 1, 13-33.

Princen, S. 2009. Agenda-Setting in the European Union. Houndsmill, Basingstoke: Palgrave.

Rogers, S. (2013) 'Tax receipts since 1963', The Guardian (Data Blog) 18 March http://www.guardian.co.uk/news/datablog/2010/apr/25/tax-receipts-1963\#data

Schrad, M.L. 2010. The Political Power of Bad Ideas: Networks, Institutions, and the Global Prohibition Wave. Oxford: Oxford University Press.

Scottish Government (2013) 'Target for tobacco-free Scotland' (News Release) http://www.scotland.gov.uk/News/Releases/2013/03/tobaccocontrol27032012

Studlar, D. (2002) Tobacco Control: Comparative Politics in the United States and Canada (Toronto: University of Toronto Press)

Studlar, D.T, Christensen, K. and Sitasari, A. (2011) "Tobacco Control in the EU-15: The Role of Member States and the European Union," Journal of European Public Policy 18 (5): 728-745.

Thom, B. (1999) Dealing With Drink (London: Free Association Books)

Thom, B. (2005) 'Who Makes Alcohol Policy: Science and Policy Networks', in Making Health Policy: Networks in Research and Policy after 1945, ed. V. Berridge. New York: Rodopi. 
Warner K. and Tam, J. (2012) 'The impact of tobacco control research on policy: 20 years of progress' Tobacco Control, 21, 2, 103-9

WHO (2008) WHO Report on the Global Tobacco Epidemic, 2008: The MPOWER Package (Geneva, Switzerland: WHO)

Yeomans, H. (2013) 'Blurred visions: experts, evidence and the promotion of moderate drinking', The Sociological Review, 61, S2, 58-78

YouGov (2012a) 'Minimum price for alcohol', March 30 http://yougov.co.uk/news/2012/03/30/minimum-price-alcohol/

YouGov (2012b) 'Minimum Alcohol Pricing - are you happy to pay more?' May 16 http://yougov.co.uk/news/2012/05/16/minimum-alcohol-pricing-are-you-happy-pay-more/

\footnotetext{
i 'Industry' describes a range of groups from independent pubs and off-licenses to large hospitality chains and supermarkets (Baggott, 2010: 137-8) and there is often competition within that broad grouping (Greenaway, 2008a: 493)

${ }^{\text {ii }}$ Challenges to the government-industry relationship come primarily from internal tensions rather than government action. For example, there are tensions between pubs and supermarkets, in the context of an increasing concentration of production in multi-national companies (Hawkins et al, 2012: 300). This might threaten its unified lobbying stand on issues such as a minimum unit price of alcohol, since it may harm pubs the least and producers/ supermarkets the most.
} 